\title{
Synthesis of Polynorbornene Containing Fluorescein Moiety
}

\author{
Mikhail Tlenkopatchev, Sergei Fomine, Edmundo Miranda, \\ Lioudmila Fomina, and Takeshi Ogawa \\ Instituto de Investigaciones en Materiales Universidad Nacional Autonoma de Mexico, \\ Apartado Postal 70-360, Coyoacan, Mexico DF, 04510
}

(Received May 8, 1995)

\begin{abstract}
A novel fluorescein-containing norbornene monomer was synthesized. This monomer copolymerized with norbornene via ring opening to give high molecular weight polymers. It gave a homopolymer with a Pd-containing catalyst opening of its double bond. All polymers exhibited absorption and emission spectra similar to those of fluorescein.

KEY WORDS Fluorescein / Norbornene / Metathesis Polymerization / Luminescence /
\end{abstract}

Chromophore functionalyzed polymers have attracted much attention and recently various new materials have been prepared; such as, $\operatorname{poly}(N \text {-vinylcarbazol })^{1,2)}$ fluorescein-tagged poly(vinyl pyrrolidone). ${ }^{3}$ Matsuo et al. $^{4}$ reported new fluorescent poly(arylene ether)s. Dharia et $a .^{5}$ reported the synthesis and characterization of wavelength-shifting polymers based on 3-hydroxyflavone. These polymers have potential applications as photoconductive resins, fluorescent labels, scintillators and photon harvesters. ${ }^{6,7}$ These "plastic scintillators" which are conveniently processed into films or fibers have faster response times than solid inorganic scintillators, and therefore they are useful in cases requiring high rates of energy analysis, such as particle accelerator facilities. The polymers containing chromofores of push-pull type also may have application in nonlinear optics..$^{8,9}$

Various fluorescein-containing polymers have been synthesized recently at the authors' laboratory. They were found to be luminescent and showed third order nonlinear optical susceptibility around $(2-3) \times 10^{-10}$ esu. $^{10}$

A number of cycloolefins bearing different functional groups have been polymerized by ring-opening metathesis polymerization
(ROMP) to yield polyalkenamers. ${ }^{1-15}$ For example, the preparation of functionalized polynorbornenes containing different chromopore $^{16,17}$ and stabilizer ${ }^{18}$ groups have been reported. The polymers which contain polar functional groups have been prepared by metathesis polymerization of the cycloolefins, by new monocomponent $\mathrm{Mo}, \mathrm{W}, \mathrm{Ru}$, and $\mathrm{Os}$ catalysts. ${ }^{19,20}$ These types of catalysts are not strong Lewis acids and initiate polymerization under mild conditions to exhibit remarkable intensitivity against polar groups. ${ }^{21}$

The present paper describes the synthesis and characterization of novel fluorescein-containing polymers by the polymerization of a norbornene containing fluorescein moiety (monomer 5) and its metathesis copolymerization with norbornene (NB) using $\mathrm{Ru}$, Os, and Pd catalysts.

\section{EXPERIMENTAL}

\section{Materials}

Polymerization solvents, chlorobenzene and toluene, were distilled over calcium hydride before use. Other reagents (Aldrich) were used as received. 


\section{Monomer Synthesis}

The synthesis of the monomer is shown in Scheme 1.

(2-Norbornene)methyltosylate (3) To a solution of (2-Norbornene)methanol $(12.4 \mathrm{~g}$, $0.1 \mathrm{~mol})$ in pyridine $(50 \mathrm{ml})$ tosyl chloride $(19.0 \mathrm{~g}, 0.1 \mathrm{~mol})$ was added at $0^{\circ} \mathrm{C}$ and the mixture was stirred overnight. The reaction mixture was poured into diluted hydrochloric acid. The oil formed was extracted with methylene chloride. The extract was washed twice with water and dried over anhydrous magnesium sulfate. The oil was dissolved in hot hexane and cooled to $-50^{\circ} \mathrm{C}$. The white solid precipitated was filtered off and dried in vacuum at room temperature. Yield $84 \%$, $T_{\mathrm{m}}=31^{\circ} \mathrm{C}$. IR $\left(\mathrm{cm}^{-1}\right) 3050(\mathrm{C}-\mathrm{H}$ arom $)$, 2968-2870 (C-H aliph), $1650(\mathrm{C}=\mathrm{C}), 1597$ $(\mathrm{C}=\mathrm{C}$, arom $), \quad 1361 \quad\left(-\mathrm{SO}_{2}-\right) .{ }^{1} \mathrm{H} \quad \mathrm{NMR}$ $\left(\mathrm{CDCl}_{3}\right)$ 0.23-2.89 (7H, aliph), $2.30(\mathrm{~s}, \cdot 3 \mathrm{H}$, $\left.\mathrm{CH}_{3}\right), 3.23-4.06\left(\mathrm{~m}, 2 \mathrm{H}, \mathrm{CH}_{2}-\mathrm{O}-\right), 5.30$ $5.95(\mathrm{~m}, 2 \mathrm{H},-\mathrm{HC}=\mathrm{CH}-), 7.06(\mathrm{~d}, 2 \mathrm{H}, 2 \mathrm{H}$ arom, orto to $\left.\mathrm{CH}_{3}\right), 7.50(\mathrm{~d}, 2 \mathrm{H}$, arom, orto to $-\mathrm{SO}_{2}$ ).
Monomer 5 Fluorescein (5g), compound 2 $(12 \mathrm{~g})$, potassium carbonate $(7 \mathrm{~g})$ and $\mathrm{N}$ methylpirrolidone $(100 \mathrm{ml})$ were stirred for 3 days at $70^{\circ} \mathrm{C}$. The reaction mixture was poured in water, and the precipitated oil was washed with water and dried in vacuum at room temperature. This oil (crude compound 4) was dissolved in methanol $(200 \mathrm{ml})$, and potassium carbonate $(2 \mathrm{~g})$ was added to the solution and the mixture was stirred for 24 hours. Methanol was partially evaporated and the residue was poured into diluted hydrochloric acid. The crude product was extracted with benzene and chromatographed on $\mathrm{SiO}_{2}$ (eluent benzeneacetone). $T_{\mathrm{m}}=142^{\circ} \mathrm{C}$, Yield $38 \% .{ }^{1} \mathrm{H}$ NMR $\left(\mathrm{CDCl}_{3}\right) 0.60-3.00$ (m, 7H (aliph)), 3.60-4.18 $\left(\mathrm{m}, 2 \mathrm{H}\left(-\mathrm{OCH}_{2}-\right)\right), 3.61\left(\mathrm{~s}, 3 \mathrm{H}\left(-\mathrm{OCH}_{3}\right)\right.$, $5.92-6.19(\mathrm{~m}, 2 \mathrm{H}(\mathrm{CH}=\mathrm{CH})), 6.44-8.32(\mathrm{~m}$, $10 \mathrm{H}$ (fluorescein moiety)). ${ }^{13} \mathrm{C} \mathrm{NMR}\left(\mathrm{CDCl}_{3}\right)$ 29.1, 38.20, 41.66, 42.30, 43.94, (aliph), 49.51 $\left(-\mathrm{CH}_{2}-\mathrm{O}-\right), 52.30\left(\mathrm{CH}_{3}-\mathrm{O}-\right), 100.8,105.7$, $113.9,114.7,117.5,128.8,129.6,129.8,130.2$, $130.6,131.1,132.1,132.6,134.6,136.2,137.0$, $138.0,150.34,154.45,159.1$ (all ring un-

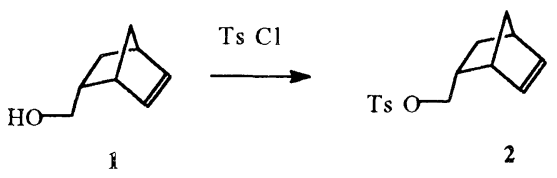

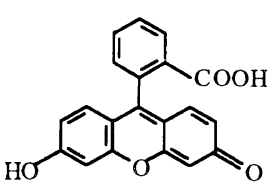

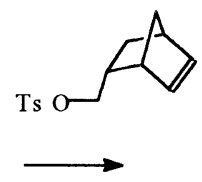

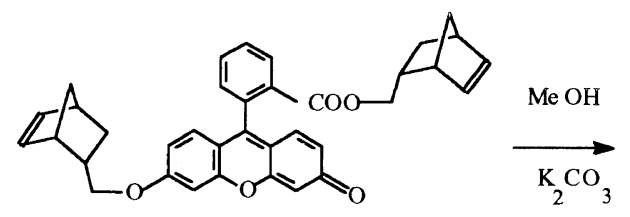

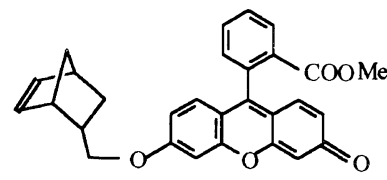

5

Scheme 1. 
saturated atoms), $163.8(\mathrm{C}=\mathrm{O}$, ester $), 185.6$ $(\mathrm{C}=\mathrm{O}$, ketone). Elemental analysis: Calcd for C, $79.80 \%, 5.54 \%$. Found C, $78.99 \%, \mathrm{H}$, $5.55 \%$.

\section{Polymerization}

The homopolymerization of monomer 5 and its metathesis copolymerization with norbornene were carried out using $\mathrm{Pd}, \mathrm{Ru}$, and Oscontaining catalysts (Table I) under a dry nitrogen atmosphere. Active metathesis catalysts were prepared by refluxing $25 \mathrm{mg}$ of commercial $\mathrm{RuCl}_{3}$ and $\mathrm{OsCl}_{3}$ hydrates in $5 \mathrm{ml}$ of $90 \%$ ethanol for 3 hours. ${ }^{16,17}$ A typical copolymerization experiment is as follows: $0.5 \mathrm{~g}$ of monomer 5 and $1 \mathrm{~g}$ of norbornene (6) were dissolved in $8 \mathrm{ml}$ of chlorobenzene under dry nitrogen. To this solution were added $2 \mathrm{ml}$ of $\mathrm{RuCl}_{3} \times \mathrm{H}_{2} \mathrm{O}$ ethanol solution $(0.027$ moll $\left.1^{-1}\right)$. The reaction was carried out at $70^{\circ} \mathrm{C}$ for 24 hours. The polymer formed was precipitated into methanol, filtered and purified by reprecipitation from $\mathrm{CHCl}_{3}$ into methanol. The reprecipitated polymer was dried in a vacuum oven at $35^{\circ} \mathrm{C}$ for 24 hours.

\section{Measurements}

FT-IR-spectra were taken using a Nikolet $510 \mathrm{p}$ spectrometer. Uv-visible spectra were taken using a Shimadzu UV-260 in chloroform. ${ }^{1} \mathrm{H}$ NMR and ${ }^{13} \mathrm{C}$ NMR spectra were taken with TMS as the internal standard in chloroform using a Varian at 300 and $75.5 \mathrm{MHz}$, respectively. Photoluminescence was measured using a Perkin-Elmer LS-2 fluorimeter in chloroform solution excitation wavelength of $310 \mathrm{~nm}$.

\section{RESULTS AND DISCUSSION}

Various catalysts containing the transition metals can induce the polymerization of norbornene and norbornene derivatives. ${ }^{22} \mathrm{~W}$, $\mathrm{Mo}, \mathrm{Ru}$, and Os catalysts polymerize norbornenes by ROMP giving poly(1,3-cyclopentenylene vinylene). ${ }^{22,23}$ The active species in ROMP is a transition metal carbene. ${ }^{22}$ However, some $\mathrm{Ti}^{24}$ and $\mathrm{Pd}^{25,26}$ catalysts are active in addition polymerization and copolymerization of norbonenes and lead to the formation of polymers which do not contain double bonds. In this case, polymerization takes place by an insertion mechanism into metall-alkyl species.

Table I. Polymerization of fluorescein-containing norbornene (NBF) and its copolymerization with norbornene (NB) by catalysts based on $\mathrm{Pd}$, Os, and $\mathrm{Ru}^{\mathrm{a}}$

\begin{tabular}{|c|c|c|c|c|c|}
\hline \multirow{2}{*}{ Run } & \multirow{2}{*}{ Catalyst } & \multirow{2}{*}{$\begin{array}{c}\text { Mole ratio } \\
5: \mathrm{NB}^{\mathrm{b}}\end{array}$} & \multirow{2}{*}[\mathrm{M}_{1}+\mathrm{M}_{2}]{$_{0}{ }^{\mathrm{c}}$} & $\begin{array}{c}\text { Polymer } \\
\text { yield }\end{array}$ & \multirow{2}{*}{$\frac{[\eta]}{\mathrm{dlg}^{-1 \mathrm{f}}}$} \\
\hline & & & & $\%^{d}$ & \\
\hline 1 & $\mathrm{RuCl}_{3} \times \mathrm{H}_{2} \mathrm{O}$ & 100 & 0.5 & - & - \\
\hline 2 & $\mathrm{RuCl}_{3} \times \mathrm{H}_{2} \mathrm{O}$ & 100 & 1.0 & - & - \\
\hline 3 & $\mathrm{OsCl}_{3} \times \mathrm{H}_{2} \mathrm{O}$ & 100 & 0.5 & - & - \\
\hline 4 & $\mathrm{PdCl}_{2}$ & 100 & 1.0 & 85 & $0.22^{\mathrm{g}}$ \\
\hline 5 & $\mathrm{Pd}(\mathrm{OAc})_{2}$ & 100 & 1.0 & 72 & $0.28^{\mathrm{g}}$ \\
\hline 6 & $\mathrm{RuCl}_{3} \times \mathrm{H}_{2} \mathrm{O}$ & $6: 94$ & 0.5 & 89 & $4.5^{\mathrm{h}}$ \\
\hline 7 & $\mathrm{RuCl}_{3} \times \mathrm{H}_{2} \mathrm{O}$ & $12: 88$ & 0.5 & 84 & $3.8^{\mathrm{h}}$ \\
\hline 8 & $\mathrm{RuCl}_{3} \times \mathrm{H}_{2} \mathrm{O}$ & $25: 75$ & 0.5 & 75 & 3.1 \\
\hline
\end{tabular}

${ }^{\text {a }}$ Polymerization was carried out in chlorobenzene for $24 \mathrm{~h}$ at $70^{\circ} \mathrm{C}$, monomer (sum of monomers) to catalyst mole ratio-100. ${ }^{\mathrm{b}}$ Feed mole ratio. ${ }^{\mathrm{c}}$ Initial monomer concentrations. ${ }^{\mathrm{d}}$ Methanol insoluble polymer. ${ }^{\mathrm{f}} \mathrm{In} \mathrm{CHCl}_{3}$ at $25^{\circ} \mathrm{C}$. ${ }^{\mathrm{g}}$ Inherent viscosity in DMSO at $25^{\circ} \mathrm{C}$. ${ }^{\mathrm{h}}$ Relative molecular weight was determined using a Varian 9012 instrument at $30^{\circ} \mathrm{C}$ in tetrahydrofuran (THF) with polystyrene standard, universal column and a flow of $1 \mathrm{ml} \mathrm{min}^{-1}$. Copolymers show $M_{n}=(5-6) \times 10^{5}$ and $M_{w} / M_{n}=2$. Other polymers was not soluble in THF. 
Table I shows that monomer $\mathbf{5}$ is not active in the ring-opening polymerization by metathesis catalysts containing $\mathrm{Ru}$ and $\mathrm{Os,}$, while $\mathrm{Pd}$ catalysts give polymer soluble in dimethyl sulfoxide (DMSO) and $N, N$-dimethyl formamide (DMF). A possible explanation for this is that the metal carbene active species formed by the reaction of the metathesis catalyst and monomer 5 does not initiate ROMP due to the steric effect of the bulky fluorescein moiety in the monomer. However, this metal carbene can propargate to NB (Table I). This means that the copolymerization proceeds by formation of an ordinary carbene active complex from NB which reacts with both NB and monomer 5. The sterically hindered metal carbene active species from monomer 5 reacts only with NB.

The polymerization of monomer 5 proceeded without ring-opening with Pd-containing catalysts by the addition mechanism giving cyclochain-containing polymers (Scheme 2 ). It is possible that in this case the steric effect of the substituent in the norbornene is less important. As can be seen from Table I monomer 5 was copolymerized with NB to high molecular weight polymers. The intrinsic and inherent viscosity of the polymers depended on the nature of the catalysts, and both were found to be in the range of 0.2 to $4.8 \mathrm{dl} \mathrm{g}^{-1}$. The copolymers obtained were soluble in common organic solvents such as chloroform, toluene, and chlorobenzene. The resulting copolymers were colored rubber like materials and could be cast from chloroform solution into flexible transparent films. They showed $5 \%$ weight loss around $300^{\circ} \mathrm{C}$ under nitrogen at heating rate of $10^{\circ} \mathrm{C} \mathrm{min}{ }^{-1}$.

${ }^{1} \mathrm{H}$ NMR spectra of monomer 5 (a), the homopolymer (b), and copolymer (c) prepared
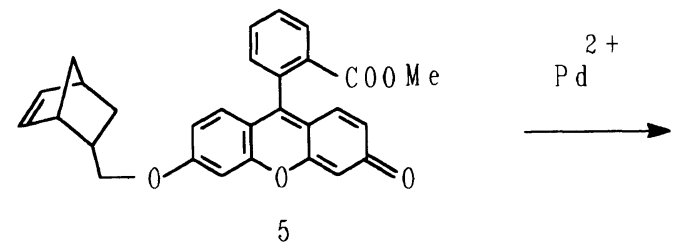

5
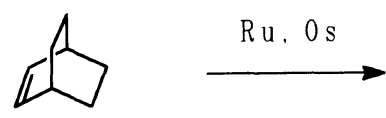
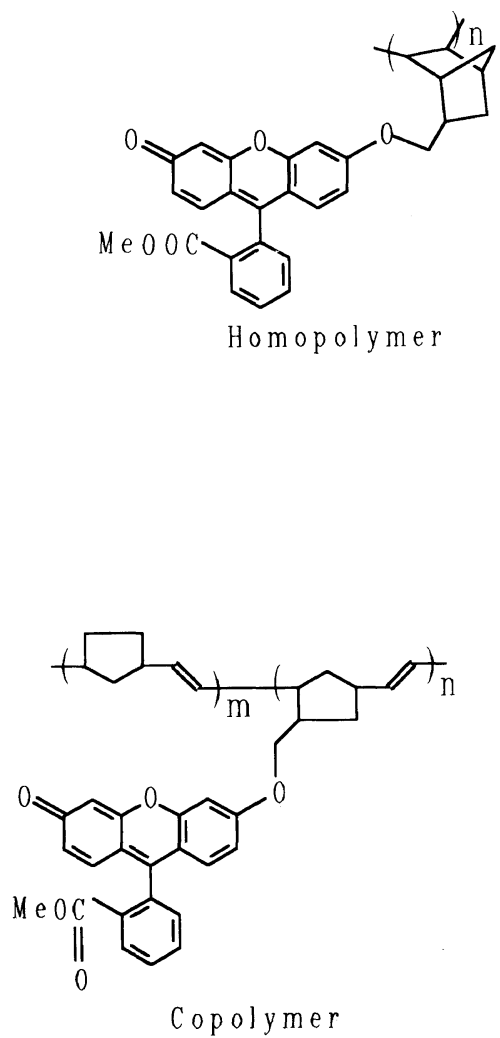

Scheme 2. 
by $\mathrm{PdCl}_{2}$ and $\mathrm{RuCl}_{3} \times \mathrm{H}_{2} \mathrm{O}$ catalysts, respectively, are shown in Figure 1. The norbornene olefin signals between $5.98-6.2 \mathrm{ppm}$ (a) dis- appeared in the spectrum of the homopolymer (b). The data of the ${ }^{13} \mathrm{C} \mathrm{NMR}$ and IR of the homopolymer also confirmed that the polym-

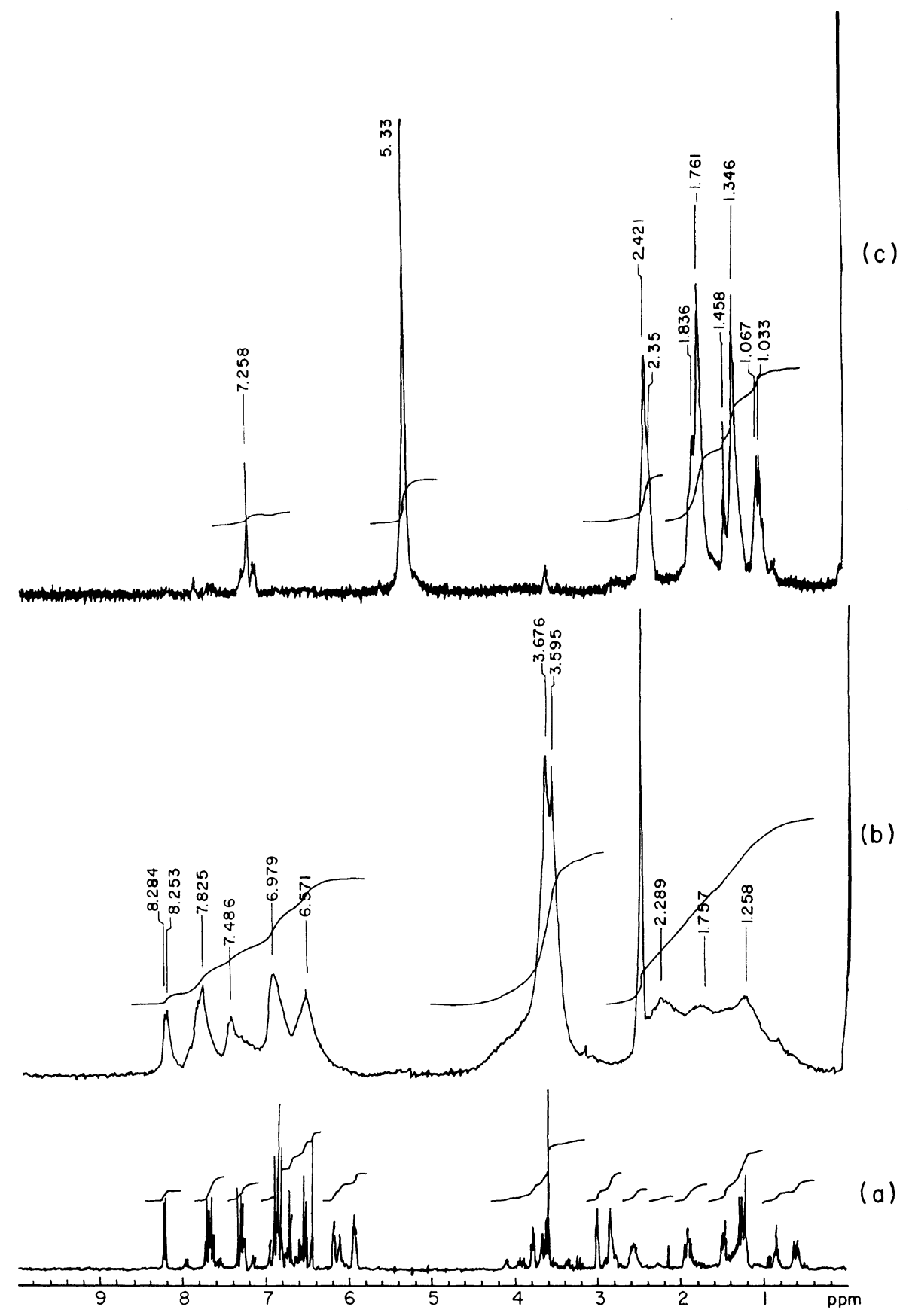

Figure 1. ${ }^{1} \mathrm{H}$ NMR spectra of monomer 5 (a), homopolymer (b), and copolymer (Table I, run 6) (c). 


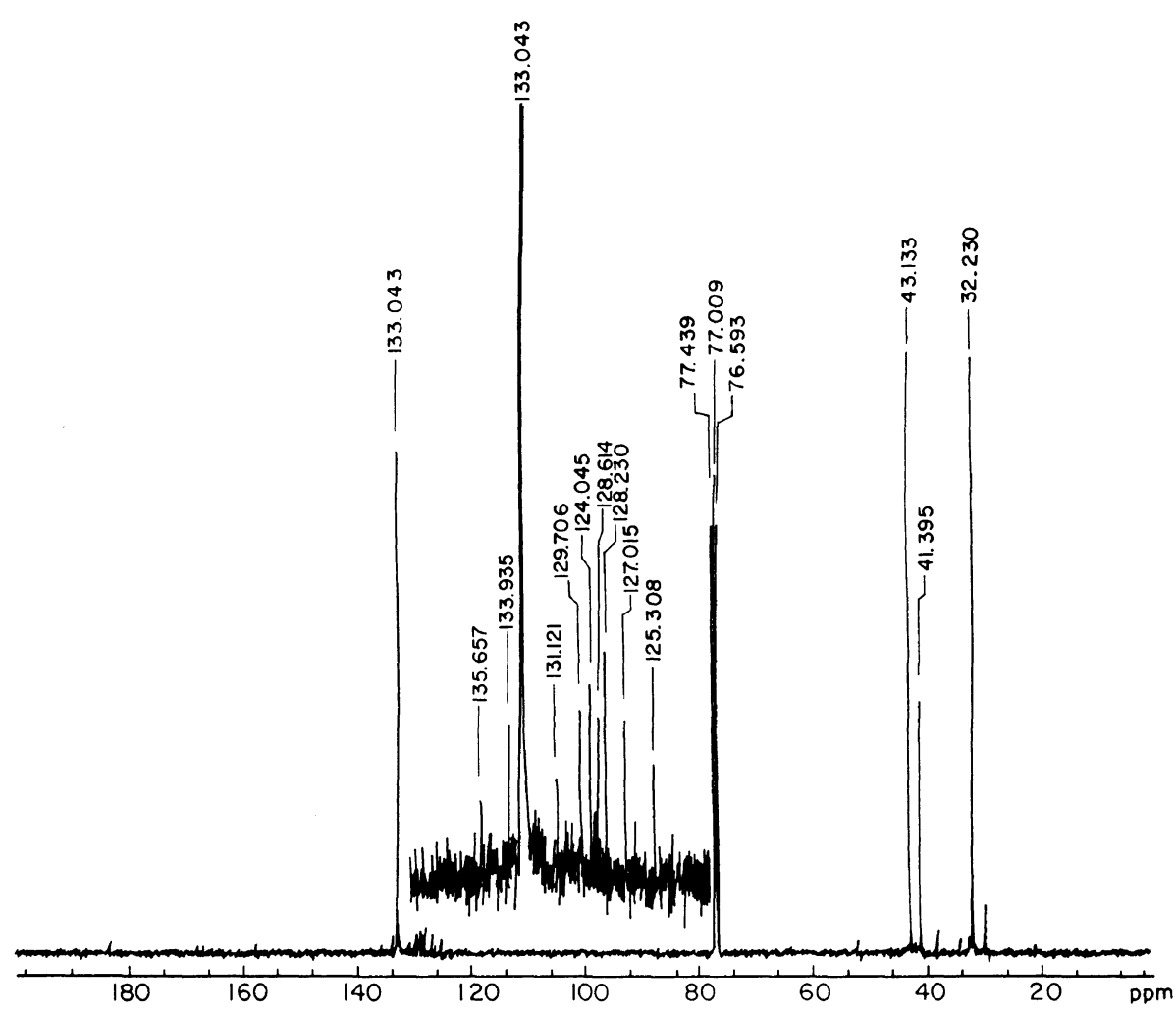

Figure 2. ${ }^{13} \mathrm{C}$ NMR spectra of copolymer (Table I, run 6).

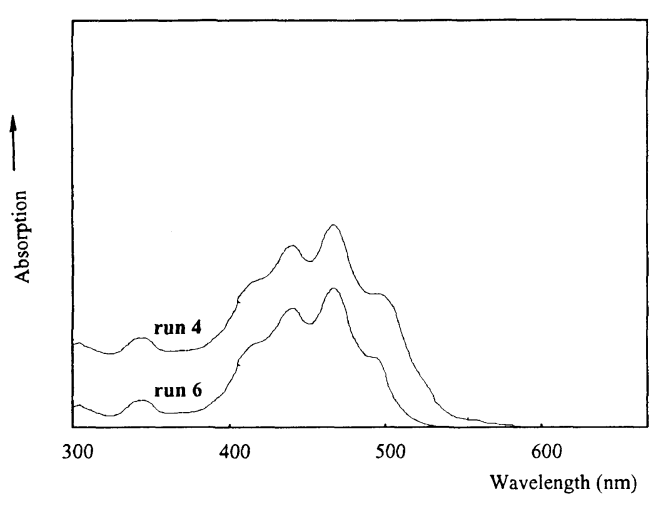

Figure 3. UV-Visible spectra of homopolymer and copolymer (Table I, runs 4 and 6).

erization of monomer 5 using Pd-containing catalysts proceded by the addition mechanism rather then ring opening. In the spectrum of monomer 5 and NB copolymer containing $12 \mathrm{~mol} \%$ monomer 5 , these monomer signals

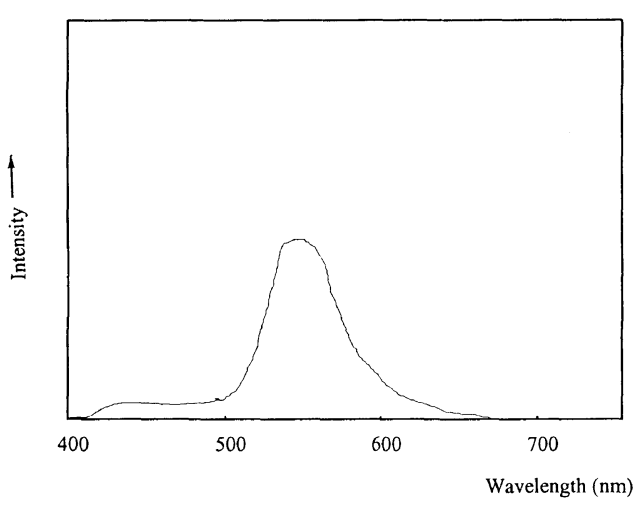

Figure 4. Luminescence spectrum of copolymer (run 6).

are replaced by a new signal with a maximum at $5.33 \mathrm{ppm}$ (Figure 1). This signal corresponds to trans olefin protons of the ring-opened norbornene structure. ${ }^{813} \mathrm{C}$ NMR spectrum of this copolymer consists of $\mathrm{CO}$ resonance at $165.5 \mathrm{ppm}$, aromatic carbons peaks at 128.6 
$125.3 \mathrm{ppm}$, olefinic signals at $135-129 \mathrm{ppm}$ and aliphatic ring-carbon peaks at $43-32 \mathrm{ppm}$ (Figure 2).

All the polymers show identical absorption bands in the visible region due to the fluorescein chromophore in each of them. Apparently, the position of the absorption maxima does not depend on the fluorescein ratio in the polymers. Examples of the visible absorption spectra of chloroform solutions of homopolymer (run 4) and of copolymer (run 6) are shown in Figure 3.

All copolymers and homopolymer exhibited luminescene in solution and films. Figure 4 shows the spectra of luminescence of diluted $\left(10^{-3} \mathrm{moll}^{-1}\right)$ chloroform solutions of copolymer (run 6). The luminescence spectrum resembled that of the fluorescene.

Acknowledgment. The authors acknowledge the financial support of CONACyT (Consejo Nacional de Ciencias y Tecnologia) under contract No. E-9406. Thanks are also due to M. A. Canseco and R. Gabiño for the accistance in thermal analysis, UV-spectroscopy, and NMR spectroscopy, respectively.

\section{REFERENCES}

1. W. Klopffer, J. Chem. Phys., 50, 2337 (1969).

2. G. E. Johnson, J. Chem. Phys., 62, 4697 (1975).

3. J. S. Hargreaves and S. E. Webber, Macromolecules, 18, 734 (1985).

4. S. Matsuo, N. Yakoh, S. Chino, M. Mitai, and S. Tagami, J. Polym. Sci., Polym. Chem. Ed., 32, 1071 (1994).

5. J. R. Dharia, K. F. Johnson, and J. B. Schlenoff, Macromolecules, 27, 5167 (1994).

6. J. Guillet, "Polym. Photophysics and Photochemistry," Cambridge University Press, New York, N.Y., 1985.
7. M. A. Winnik, Acc. Chem. Res., 18, 83 (1985).

8. D. S. Chemla and J. Zyss, "Nonlinear Optical Properties of Organic Molecules and Crystals, Vols. 1 and 2, Y. H. Pao, Ed., Academic Press, Orlando, 1987.

9. P. N. Prasad and D. J. Williams, "Introduction to Nonlinear Optical Effects in Molecules and Polymers," John-Wiley Sons, New York, N.Y., 1991.

10. S. Fomine, A. Pineda, T. Ogawa, Perez, and M. Sotelo, Polym. J., 27, 712 (1995).

11. S. Matsumoto, K. Komatsu, and K. Igarishi, Polym. Prepr. (Am. Chem. Soc., Div. Polym. Chem.), 18 (1), 110 (1977).

12. S. Ramakrishna and T. C. Chung, Macromolecules, 22, 2183 (1989).

13. G. C. Bazan, R. R. Schrock, H. N. Cho, and V. C. Gibson, Macromolecules, 244495 (1991).

14. E. Sh. Finkelshtein, K. L. Makovetskii, Yu. P. Yampol'skii, E. B. Portnykh, I. A. Ostrovskaya, N. E. Kaliujzhnyi, N. A. Pritula, A. I. Gol'berg, U. S. Yatsenko, and N. A. Platé, Makromol. Chem., 192, 1 (1991).

15. J. Asrar, Macromolecules, 25, 5150 (1992).

16. J. H. Lee, J. W. Park, J. M. Ko, Y. H. Chang, and S.-K. Choi, Polym. Bull., 31, 339 (1993).

17. A. Laschewsky and W. Schulz-Hanke, Makromol. Chem., Rapid Commun., 14, 683 (1993).

18. M. A. Tlenkopatchev, E. Mirando, M. A. Canseco, R. Gaviño, and T. Ogawa, Polym. Bull., 34, 385 (1995).

19. J. S. Murdzek and R. R. Schrock, Macromolecules, 20, 2460 (1987).

20. B. M. Novak and R. H. Grubbs, J. Am. Chem. Soc., 110, 960 (1988).

21. M. C. Hillmyer, C. Lepetit, D. V. McGrath, B. M. Novak, and R. H. Grubbs, Macromolecules, 25, 3345 (1992).

22. K. J. Ivin, "Olefin Metathesis," Wiley-Interscience, Chichester, 1985.

23. B. M. Novak and R. H. Grubbs, J. Am. Chem. Soc., 110, 7542 (1988).

24. G. Sartori, F. C. Ciampelli, and N. Cameli, Chim. Ind. (Milan), 45, 1478 (1963).

25. R. G. Schulz, J. Polym. Sci., Polym. Lett. Ed., 4, 541 (1966).

26. Ch. Mehler and W. Risse, Makromol. Chem., Rapid Commun., 12, 255 (1991). 